\title{
XXII. On the equation of continuity in fluid motion
}

\section{Alfred William Hobson B.A.}

To cite this article: Alfred William Hobson B.A. (1847) XXII. On the equation of continuity in fluid motion, Philosophical Magazine Series 3, 30:199, 104-107, DOI: 10.1080/14786444708645661

To link to this article: http://dx.doi.org/10.1080/14786444708645661

曲 Published online: 30 Apr 2009.

Submit your article to this journal $\sqsubset$

Џll Article views: 3

Q View related articles $ک$ 
chemical action of an acid solution on a metal gives signs of electrical disturbance on the condenser; the physical force of magnetism produces by induction an instantaneous disturbance in the natural electrical fluid of a metallic wire, without setting it in a continuous current. But when two forces are in action, one of which is capable of disturbing the natural electricity of the ponderable matter, and the other of evolving it from the integrant molecules of the same, that fluid may be set into a continuous current in a complete circuit. Notwithstanding the appearance of truth in this mode of explaining the phænomenon of the continuous electric current, there are some facts which merit a deeper investigation, aided by experiment, before assigning it as the just cause of this phænomenon. A voltaic pair composed of two different metals, for example, gives an electric current in a given direction when it is immersed in one liquid, and the direction may be inverted when another different liquid is substituted for the first. The examination of facts of this kind will probably furnish materials for a second note.

XXII. On the Equation of Continuity in Fluid Motion. By Alfred Wiluiam Hobson, B.A. St. John's College, Cambridge*.

THE proof of this equation given by the various authors of treatises on hydrodynamics is the same in all; in fact nearly every writer since Poisson has contented himself with a mere translation of his words in art. 64.8 of his Traité de Mécanique. As however 1 do not remember to have seen anywhere a statement of the reasons for the assumption from which the equation is obtained, the following investigation may be interesting to some, especially as the equation itself is found by a much shorter process than the usual one, and unencumbered with several steps which are perhaps not quite satisfactory to those reading the common method for the first time.

The fluid is supposed to be divided into small portions or ' elements,' each of which is acted upon by accelerating forces $\mathrm{X}, \mathrm{Y}, \mathrm{Z}$ parallel to the coordinate axes. The first thing to be remarked is that $\mathrm{X}, \mathrm{Y}, \mathrm{Z}$ must be the same for the rohole extent of the element on which they are supposed to act, i.e. we must take the element so small that there is no variation in either $\mathrm{X}, \mathrm{Y}$ or $\mathrm{Z}$ in passing from any one of its parts to another. Now since these forces are considered as functions of $(x, y, z)$ varying for any, the slightest variation in either $x$, $y$ or $z$, it is plain that if we consider the forces mathematically

* Communicated by the Author. 
continuous, $i . c$. as changing their value continuously for any change of $x, y$ or $z$, then in order for $\mathrm{X}, \mathrm{Y}, Z$ to be the same for every part of an element, that element must be also considered a mathematical point, having no distinction of parts at all.

In nature, however, the forces are physically and not mathematically continuous, and the elements on which they act may have an infinite range of magnitude. The reasoning by which such forces are submitted to calculation is however precisely the same as if they were mathematically continuous.

The element of fluid, then, may be of any finite magnitude below a certain limit, and will consist of a number of ultimate particles, on each of which the forces acting are the same. For the whole extent of this element $X, Y, Z$ are the same, and it may be taken of any size consistent with this condition.

The next thing to be attended to is, that the element must not be acted upon by any new forces during the instant $(d t)$. During this interval, therefore, every particle in the element is acted upon solely by the forces $\mathrm{X}, \mathrm{Y}, \mathrm{Z}$, which vary or may vary with the time, but vary similarly for each of these particles. In other words, there is no disturbing force introduced during $(d t)$ into the system of ultimate particles, which together make up the element we are considering; therefore there can be no disturbance of the relative positions of these particles. Therefore the number of particles composing the element remains the same during the interval $(d t)$; and this condition expressed analytically gives us the equation of continuity.

Let $\rho$ be the density of the element at the commencement of the time $(d t)$; this is supposed to be the same for the whole of the element; $\mathrm{V}$ the volume of the element at the beginning of $(d t)$ and $\mathrm{V}^{\prime}$ at the end. We have then ( $\rho^{\prime}$ being also the density at the end of the time $(d t))$

$$
\rho \mathrm{V}=\rho^{\prime} \mathrm{V}^{\prime} \text {. }
$$

We have now merely to express this condition in another form. The notation is the same as Poisson's. $\mathrm{V}=\left(x^{\prime}-x\right)\left(y^{\prime}-y\right)$ $\left(z^{\prime}-z\right)$ : where for $\left(x^{\prime}-x\right)$ we may write $\delta x$, for $\left(y^{\prime}-y\right), \delta y$, and for $\left(z^{\prime}-z\right), \delta z$. We have to state in terms of the velocities $(u, v, w)$ parallel to the coordinate axes, that the variation of $\left(x^{\prime}-x\right)\left(y^{\prime}-y\right)\left(z^{\prime}-z\right) \rho$ is nothing during the instant $(d t)$. Now calling the whole differential coefficient of $\left(x^{\prime}-x\right)\left(y^{\prime}-y\right)\left(z^{\prime}-z\right)$ with regard to the time $D_{t} V$, and similarly for that of $\rho$,

$$
\begin{gathered}
\mathrm{D}_{t} \mathrm{~V}=\left(x^{\prime}-x\right)\left(y^{\prime}-y\right)\left(w^{\prime}-w\right)+\left(x^{\prime}-x\right)\left(z^{\prime}-z\right)\left(v^{\prime}-v\right) \\
+\left(y^{\prime}-y\right)\left(z^{\prime}-z\right)\left(u^{\prime}-u\right)
\end{gathered}
$$

Phil. Mag. S. 3. Vol. 30. No. 199. Feb. 1847. 


$$
\begin{aligned}
=\delta x . \delta y \cdot & \left(\frac{d w}{d x} \delta x+\frac{d w}{d y} \delta y+\frac{d w}{d z} \delta z\right)+\delta x \cdot \delta z\left(\frac{d v}{d x} \delta x+\frac{d v}{d y}\right. \\
\left.\delta y+\frac{d v}{d z} \delta z\right) & \\
+ & \delta y \cdot \delta z \cdot\left(\frac{d u}{d x} \delta x+\frac{d u}{d y} \delta y+\frac{d u}{d z} \delta z\right) \\
= & \delta x \cdot \delta y \cdot \delta z\left[\frac{d u}{d x}+\frac{d v}{d y}+\frac{d w}{d z}\right] \\
+\delta x \cdot \delta y \cdot \delta z \cdot & {\left[\frac{d u}{d y} \cdot \frac{\delta y}{\delta x}+\frac{d u}{d z} \cdot \frac{\delta z}{\delta x}+\frac{d v}{d x} \cdot \frac{\delta x}{\delta y}+\frac{d v}{d z} \cdot \frac{\delta z}{\delta y}+\frac{d w}{d x} \cdot \frac{\delta x}{\delta z}\right.} \\
& \left.+\frac{d w}{d y} \cdot \frac{\delta y}{\delta z}\right] . \\
\mathrm{D}_{t \rho} & =\frac{d \rho}{d t}+u \cdot \frac{d \rho}{d x}+v \cdot \frac{d \rho}{d y}+w \cdot \frac{d \rho}{d z} ;
\end{aligned}
$$

$\therefore$ we have

$$
\mathrm{D}_{t}(\rho \mathrm{V})=0, \quad \text { or } \rho \cdot \mathrm{D}_{t} \mathrm{~V}+\mathrm{V} \cdot \mathrm{D}_{t \rho}=0 \text {; }
$$

or

$$
\begin{gathered}
\rho . \delta x . \delta y . \delta z \cdot\left(\frac{d u}{d x}+\frac{d v}{d y}+\frac{d w}{d z}\right)+\rho \cdot \delta x \cdot \delta y \cdot \delta z \cdot\left(\frac{d u}{d y} \cdot \frac{\delta y}{\delta x}+\frac{d u}{d z} \cdot \frac{\delta z}{\delta x}+\& \mathbf{c} .\right) \\
+\delta x \cdot \delta y \cdot \delta z\left(\frac{d \rho}{d t}+u \cdot \frac{d \rho}{d x}+v \cdot \frac{d \rho}{d y}+w \cdot \frac{d \rho}{d z}\right)=0 .
\end{gathered}
$$

Now since there is no necessary connexion between $\delta x, \delta y$ and $\delta z$, the middle term in this equation, viz. that containing the quantities $\frac{\delta y}{\delta x}$, \&c., cannot affect the other two: according therefore to a well-known principle, the two parts must separately $=$ zero.

Therefore, finally, dividing out by the common factor $\delta x$. $\delta y . \delta z$, we get the usual equation of continuity,

or:

$$
\rho\left(\frac{d u}{d x}+\frac{d v}{d y}+\frac{d w}{d z}\right)+\frac{d \rho}{d t}+u \cdot \frac{d \rho}{d x}+v \cdot \frac{d \rho}{d y}+v \cdot \frac{d \rho}{d z}=0 ;
$$

$$
\frac{d \rho}{d t}+\frac{d(\rho u)}{d x}+\frac{d(\rho v)}{d y}+\frac{d(\rho w)}{d z}=0 \text {. }
$$

It is obvious that this equation only requires that the number of particles in the element should remain unaltered during $(d t)$; but the mode in which it is obtained implies, not only an identity in the number of particles at the beginning and end of $(d t)$, but an identity of the particles themselves. 'This observation has also been made by Poisson, whose words are (art. 651), "c'est pour abreger que l'on a considéré le volume de cette partie du fluide comme infiniment petit; et si l'on divise 
le volume total en parties de grandeur finie, mais insensible, dont chacune renferme neanmoins un nombre extremement grand de molecules l'equation [of continuity] exprime réellement que chacune de ces parties renferme toujours les mêmes molecules, et que par conséquent sa masse est invariable."

In all cases where new forces are being continually introduced, as in the flowing of rivers or of water through pipes of variable form, it is impossible to calculate the motion, and at the same time the equation of continuity is no longer applicable. But, on the other hand, there are cases in which this equation holds, where nevertheless the other three equations of motion do not hold, and in fact where there may actually occur a split or division in the fluid. As an instance may be mentioned the flowing of a stream of water over the edge of a perpendicular precipice, where gravity suddenly comes into action. In this case the number of particles may remain the same in an element which may be conceived to consist of particles that have fallen over as well as of those that remain. But the equation of motion would require the new force of gravity to be taken into account.

XXIII. On the Integration of some Equations in Partial Differentials. By the Rev. Brice Bronwin*.

$\mathbf{N}$ the present paper $\mathrm{I}$ shall extend the mode of integrating certain differential equations, which I gave in this Journal in December last, to the integration of similar equations in partial differentials. Let $\mathrm{D}$ stand for $\frac{d}{d x}, \mathrm{D}^{\prime}$ for $\frac{d}{d y}$; and as a first example, let

$$
x\left(\frac{d^{2} z}{d x^{2}}-a^{2} \frac{d^{2} z}{d y^{2}}\right)+2 p \frac{d z}{d x}=0,
$$

where $p$, as throughout the paper, is a positive integer. Make

then

$$
\begin{gathered}
a \mathrm{D}^{\prime} \sqrt{-1}=k, \\
x\left(\frac{d^{2} z}{d x^{2}}+k^{2} z\right)+2 p \frac{d z}{d x}=0 .
\end{gathered}
$$

This is the first example in the paper above referred to, where by making $z=\left(D^{2}+k^{2}\right)^{p} u$, it is reduced to

$$
\frac{d^{2} u}{d x^{2}}+k^{2} u=0
$$

or, restoring the suppressed factor, to

$$
\left(\mathrm{D}^{2}+k^{2}\right)^{p} x\left(\mathrm{D}^{2}+k^{2}\right) u=0 \text {. }
$$

- Communicated by the Author. 